\title{
Site-selective photofragmentation of chlorinated polymeric films observed around the chlorine $K$-edge
}

\author{
C. Arantes ${ }^{\mathrm{a}, *}$, L.A.V. Mendes ${ }^{\mathrm{b}}$, R.R. Pinho ${ }^{\mathrm{c}}$, M. Ferreira ${ }^{\mathrm{d}}$, G.G.B. de Souza ${ }^{\mathrm{e}}$, A.B. Rocha ${ }^{\mathrm{e}}$, M.L.M. Rocco ${ }^{\mathrm{e}}$ \\ a Divisão de Metrologia de Materiais, Instituto Nacional de Metrologia, Qualidade e Tecnologia, Xerém 25250-020, Duque de Caxias, RJ, Brazil \\ ${ }^{\mathrm{b}}$ Instituto de Física, Universidade Federal da Bahia, Ondina, 40210-340 Salvador, BA, Brazil \\ ' Departamento de Física-ICE, Universidade Federal de Juiz de Fora, Campus Universitário, 36036-330 Juiz de Fora, MG, Brazil \\ d PEMM/COPPE, Universidade Federal do Rio de Janeiro, Cidade Universitária, Ilha do Fundão, 21941-972 Rio de Janeiro, RJ, Brazil \\ e Instituto de Química, Universidade Federal do Rio de Janeiro, Cidade Universitária, Ilha do Fundão, 21941-909 Rio de Janeiro, RJ, Brazil
}

\section{A R T I C L E I N F O}

\section{Article history:}

Received 31 August 2012

In final form 7 January 2013

Available online 26 January 2013

\section{Keywords:}

Photon stimulated ion desorption (PSID)

Chlorinated polymers

Poly(vinyl chloride) (PVC)

Poly(vinyl dichloride) (PVDC)

Synchrotron radiation

Spectator Auger process

$\mathrm{X}$-ray induced electron stimulated

desorption (XESD)

Quantum mechanical calculations

\begin{abstract}
A B S T R A C T
Photon stimulated ion desorption (PSID) and Near-edge X-ray absorption fine structure (NEXAFS) studies have been performed on poly(vinyl chloride) (PVC) and poly(vinyl dichloride) (PVDC) around the chlorine 1s-edge. Experiments were performed using a synchrotron source operating in the single-bunch mode and a time-of-flight mass spectrometry for ion analysis. $\mathrm{Cl}^{+}$ion yields, as a function of the photon energy, reproduce the photoabsorption spectrum, showing significant increase at the 1s-resonance. Edge-jump ratios, defined as the ratio between edge-jumps (intensity ratio of the yields between above and below the absorption edge) of two different transitions, for $\mathrm{Cl}^{+}$ion yields were much higher than the equivalent electron yields, indicating site-selectivity in $\mathrm{C}-\mathrm{Cl}$ bond breaking for both polymers, as a result of efficient spectator Auger decay. The expected isotope ratio of 3:1 for chlorine was measured for PVC. The interpretation of the NEXAFS spectrum was assisted by quantum mechanical calculations at a multireference perturbation theory level.
\end{abstract}

(c) 2013 Elsevier B.V. All rights reserved.

\section{Introduction}

Chlorinated polymers have already shown a wide variety of applications, such as in the pharmaceutical, food package and cosmetic industries $[1,2]$. Their thin films have been also applied to produce biocomposites and sensors [3,4].

Ion desorption generated by photoexcitation at shallow and deep core levels has already proved to be an attractive topic in surface science since it is a surface phenomena that allows to investigate composition, electronic structure and site-selective fragmentation. Mainly interested in fundamental aspects, our group has performed several previous studies using small chlorinated molecules [5] or polymers, such as poly(vinyl chloride) (PVC) and poly(vinyl dichloride) (PVDC) [6-10], using electrons or high energy photons as excitation sources. In particular, our previous photon stimulated ion desorption (PSID) studies performed on PVC and PVDC films with photon energies covering the valence, $\mathrm{Cl} 2 \mathrm{p}$ and $\mathrm{C} 1 \mathrm{~s}$ energy ranges showed element-selectivity as

\footnotetext{
* Corresponding author. Tel.: +55 212679 9810; fax: +55 2126799021.

E-mail address: csilva@inmetro.gov.br (C. Arantes).
}

evidenced by an increase in the chlorine ion yield around the $\mathrm{Cl}$ 2p-edge as compared to the other excitation energies. This feature was associated to a resonant Auger process along the $\mathrm{Cl} 2 \mathrm{p}$-edge $[9,10]$. Similar ion desorption results were obtained for PVDC [10]. Positive and negative electron stimulated ion desorption (ESID) performed on PVC films as a function of the electron energy indicated that at higher electron energies, inner-shell ionization processes followed by Auger decay play an important role in the positive ion desorption of chlorine species. On the other hand, the formation of negative chlorine ionic species was strongly enhanced around the $\mathrm{Cl} 2$ p-edge [8].

Studies applying low energy ion bombardment have shown that PVC surfaces are also sensitive to this kind of radiation. The extent of surface modification is dependent on the radiofrequency power to excite the discharge and the amount of energy deposited on the solid surface. Polymers may become more hydrophilic or hydrophobic than the pristine material depending on the process condition [11].

A number of studies have demonstrated that following excitation or ionization of an inner-shell electron and the corresponding relaxation through the Auger process, which predominates for light elements, fragmentation is observed around the atom to which the inner-shell electron is closely associated [12]. This is 
very well described in the literature $[13,14]$ and can explain ion desorption in different organic and polymeric films due to the formation of localized positive holes in valence orbitals, leading to fragmentation and desorption through the Coulomb explosion mechanism. The importance of the spectator Auger decay in inducing selectivity in chemical bond breaking has already been stressed, even in deep core-level photoexcitation around the $K$ edges of adsorbed molecules containing third-row elements [15]. The indirect process named X-ray induced electron stimulated desorption (XESD) also contributes to ionic desorption. In this process desorption from surface species due to valence excitations and ionizations is induced by low energy electrons inelastically scattered inside the sample.

In the present study, NEXAFS (Near-edge X-ray absorption fine structure) and PSID spectra were acquired at the chlorine 1s-edge for PVC and PVDC, two chlorinated polymers containing a different number of chlorine atoms, in order to gain insight into the photofragmentation process induced by a deep core level, by comparing the contributions from direct (Auger) and indirect (secondary electrons) mechanisms to ionic desorption. Also the purpose of the work is to complement fragmentation studies performed previously on these films covering other energy intervals, ranging from valence to shallow inner-shell excitations [6-10]. The $\mathrm{Cl} 1$ s-edge was selected in order to evaluate possible improvements in the site-selectivity fragmentation of the $\mathrm{C}-\mathrm{Cl}$ bond caused by chlorine core-shell excitation, since it is expected that excitation of localized electrons may favor selective bond breaking. It is worthwhile mentioning that the only structural difference between these two chlorinated polymers is the addition of one chlorine atom in the PVDC structure (insert: Fig. 1).

Additionally, ab initio calculations are reported, showing to be quite helpful in the interpretation of the NEXAFS spectra and also PSID ion yields. It is worth emphasizing that the accurate description of inner-shell states of a polymer represents an enormous challenge to $\mathrm{ab}$ initio methods. In principle, one has to consider the description of a periodic (infinite) system. In the case we are dealing with, this can be easily circumvented by rationalizing the polymer spectrum in terms of the spectrum of the corresponding monomer. The theoretical description of the monomer has some intrinsic difficulties as well, since relaxation, correlation and, sometimes, localization effects have to be properly taken into account. For chlorine 1s states, relativistic effects are important and should also be considered.

Both direct and indirect processes are invoked to explain PSID results of PVC and PVDC. Clear evidence of chemical bond breaking controlled by a deep core level excitation is presented.

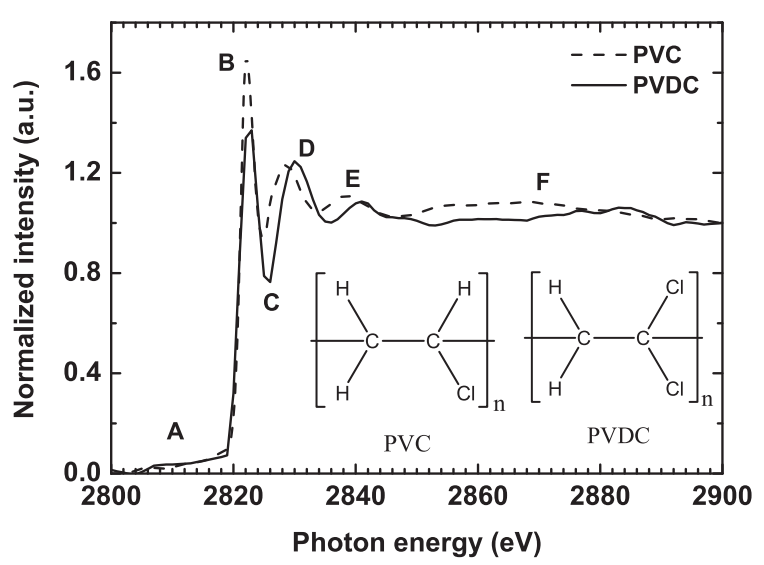

Fig. 1. $\mathrm{Cl} K$-edge TEY NEXAFS spectra of (dash line) PVC and (solid line) PVDC films. The inset shows the molecular structure of PVC and PVDC.

\section{Experimental details}

Thin films of PVC and PVDC were deposited onto a stainlesssteel substrate by the spin-coating technique. The samples were attached to an aluminum support which, on its turn, was mounted onto an $X-Y-Z$ sample manipulator.

NEXAFS and PSID spectra were acquired at the Brazilian synchrotron light source (LNLS), during a single-bunch operation mode of the storage ring with a period of $311 \mathrm{~ns}$ and width of $60 \mathrm{ps}$. The sample chamber was attached to a soft X-ray spectroscopy (SXS) beamline (790-4000 eV) featuring a double-crystal type monochromator. When using the InSb (111) plane, an energy resolution of $\sim 2.8 \mathrm{eV}$ at $4 \mathrm{keV}$ was attained [16]. A schematic diagram of the experimental setup used at LNLS for PSID measurements can be found in previous publication [17].

Photoabsorption (NEXAFS) spectra were recorded by measuring the drain current at the sample (total electron yield - TEY) simultaneously with a photon flux monitor (Au grid). The final data were normalized to these flux spectra in order to correct for fluctuations in beam intensity. The energy calibration was performed by taking the well-known value for the $\mathrm{L}_{\mathrm{III}}$ transition $\left(2 \mathrm{p}_{3 / 2} \rightarrow 4 \mathrm{~d}\right)$ of metallic molybdenum [18].

Ion analysis was performed using a time-of-flight mass spectrometer (TOF-MS), consisting basically of an electrostatic ion extraction system, a collimating electrostatic lens, a $25 \mathrm{~cm}$ drift tube and a pair of microchannel plate (MCP) detectors, disposed in a chevron configuration [19]. The extracted positive ions travel through three metallic grids (each of which with a nominal transmission of $90 \%$ ), before reaching the MCP. The output signal of the detector was processed by a standard pulse counting system and used to provide the stop signal to the TDC (Time-to-Digital Converter), with a maximum time resolution of 1 ns per channel. The trigger of the experiment and also the start signal for the TDC were obtained by a 1/148 divider used to take the SR pulse timing from the $476.066 \mathrm{MHz}$ frequency signal from the microwave cavity of the storage ring. Positive ions were extracted from the sample biased at $+1.5 \mathrm{kV}$ through the entrance grid of the TOF-MS placed at $-2.0 \mathrm{kV}$ and were further collimated and transmitted through the drift tube, which was kept at a potential of $-2.0 \mathrm{kV}$. Finally, the ions were detected by the MCP, biased at $-4.5 \mathrm{kV}$. The program SIMION 3D 6.0 [20] was used in order to simulate the ion flight times and assign the positive ion masses, using a procedure described in detail elsewhere [21].

\section{Theoretical details}

As mentioned above, theoretical calculations were performed on the monomers, i.e., chloroethane, and 1,1-dichloroethane. Properties of interest are transition energies and oscillator strengths. The theoretical description adopted here was the following. First, a state-averaged multiconfigurational self consistent field (MCSCF) calculation is performed. The configurations in this MCSCF calculation includes the Hartree-Fock (HF) configuration for the ground state and as many configuration as needed for a HF-like description of the core-hole excited state. For chloroethane, this means only one configuration while for 1,1-dichloethane, two configurations are employed, each one corresponding to an excitation from each chlorine atom. This method may also be considered as a state-averaged Hartree-Fock. Subsequently, correlation effects are treated by general multiconfiguration self-consistent field quasi-degenerate perturbation theory (GMC-QDPT) [22], taking the previous MCSCF as zeroth-order function. Scalar relativistic contribution to the transition energy and oscillator strengths is calculated by DouglasKroll-Hess [23,24] method corrected to third order [25]. 
All calculations were done with Dunning's aug-cc-pVTZ basis set and using the GAMESS [28] software.

\section{Results and discussion}

Photoabsorption (NEXAFS) spectra of PVC and PVDC films measured at the $\mathrm{Cl} 1 \mathrm{~s}$-edge are presented in Fig. 1. These spectra show features, labeled B-E, which correspond to transitions from the $1 \mathrm{~s}$ chlorine electron to unoccupied orbitals. The intense peak B at $2822 \mathrm{eV}$, for both polymers, may be related to a transition to an antibonding molecular orbital, while the other features are associated to transitions to valence and Rydberg states, as observed in other chlorinated molecules [5]. PVDC film presents lower relative intensity by a factor of 0.23 for the first transition energy (B), as well as a shift of $1.7 \mathrm{eV}$ and $2.4 \mathrm{eV}$ for the $\mathrm{D}$ and $\mathrm{E}$ transitions to higher photon energies, respectively. The two chlorine atoms in the PVDC induce a higher repulsion between valence electrons. An electron in a Rydberg state will suffer a greater repulsion as well and will tend to be more loosely bound. This explains the shift to higher energies when passing from PVC to PVDC. Calculated C$\mathrm{Cl}$ bond distance at MP2 level for chloroethane and 1,1-dichloroethane are 1.78 and $1.77 \AA$, respectively. The difference is within the precision of the method. So, they should be considered as equal.

An interesting feature apparent in Fig. 1 is the observed intensity difference at peak (B). Naively, one could imagine that PVDC would present a more intense absorption due to the presence of an additional chlorine atom but actually the opposite is true, i.e.,

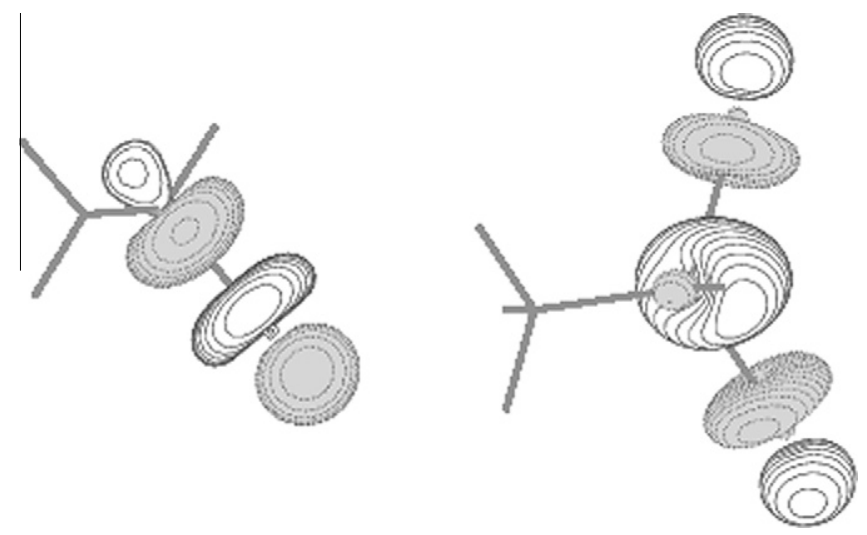

Fig. 2. Final orbital for chloroethane (left) and 1,1-dichloroethane (right). Grey and white colours represent different sign (positive or negative) of the wave function. Antibonding character is recognized in the node along $\mathrm{C}-\mathrm{Cl}$ axis. For 1,1-dichloroethane the orbital is distributed along both $\mathrm{C}-\mathrm{Cl}$ bonds.
PVC presents the most intense peak. In order to clarify this point, we have performed calculations for this transition. It corresponds to the first singlet-to-singlet transition. Our theoretical results for the oscillator strengths are 0.0058 for chloroethane and 0.0045 and 0.0008 for 1,1 -dichloroethane, respectively. In the 1,1-dichloroethane case, two states lie quite close. They correspond to configurations representing transition from each $\mathrm{Cl} 1 \mathrm{~s}$ orbital to the same final orbital. It is worth emphasizing that although localized orbitals have been used, the total symmetry is recovered since both configurations contribute to the final state. The oscillator strength in the latter case should be summed and compared to that of chloroethane. The values are 0.0058 and 0.0053 for chloroethane and 1,1-dichloroethane, respectively. We therefore conclude that even after summing up both contributions in 1,1-dichloroethane, the intensity of absorption is still smaller than that of chloroethane. The experimental values presented in Fig. 1 show the same trend.

The calculated transition energies are $2831.39 \mathrm{eV}$ for chloroethane and 2825.53 and $2825.57 \mathrm{eV}$ for 1,1-dichloroethane. These values differ from the experimental value for peak (B) in Fig. 1, which lies at $2822 \mathrm{eV}$. These differences can be related to several causes. First, we only took into account the relativistic effects considered in the Douglas-Kroll Hamiltonian. Besides, correlation is only partially taken into account and the spectrum is considered to be similar to the spectra of the monomers. At any rate, the maximum deviation for the transition energy is less than $0.5 \%$.

Another important result obtained from our calculation is the confirmation of the antibonding character of the molecular orbital involved in the first $\mathrm{Cl} 1 \mathrm{~s}$-electronic transition. It is concentrated in the $\mathrm{C}-\mathrm{Cl}$ bond in the case of PVC and distributed along both $\mathrm{C}-\mathrm{Cl}$ bonds for PVDC as can be clearly seen in Fig. 2 .

PSID spectra for PVC and PVDC films were acquired at the energies labeled A-F in Fig. 1. PSID spectra for both chlorinated polymers measured at $2800 \mathrm{eV}$ (A) and $2822 \mathrm{eV}$ (B) are presented in Fig. 3(a)-(d). The spectra present many fragments, whose assignments are listed in Tables 1 and 2, using a procedure described elsewhere [21]. $\mathrm{H}^{+}$and $\mathrm{Cl}^{+}$isotopes can be seen directly from the spectra. Larger hydrocarbon fragments, as well as chlorine-based fragments are labeled in Tables 1 and 2.

In order to determine the ${ }^{35} \mathrm{Cl}:{ }^{37} \mathrm{Cl}$ isotope ratio expected for the $\mathrm{Cl}^{+}$species, we have fitted and deconvoluted the isotope peaks with Gaussian functions and a constant baseline as background. ${ }^{35} \mathrm{Cl}:{ }^{37} \mathrm{Cl}$ ratios obtained from peak areas were 2.6 and 1.7 for PVC and PVDC films, respectively. This indicates that PVC presents around the 3:1 isotope ratio as expected [26]. PVDC presents lower relative intensity for ${ }^{35} \mathrm{Cl}$ species as compared to PVC.

Studies performed by our group [8] using high energy electron incidence on PVC films have shown that species with masses higher than $m / z 65$ are either not formed or are reneutralized on the
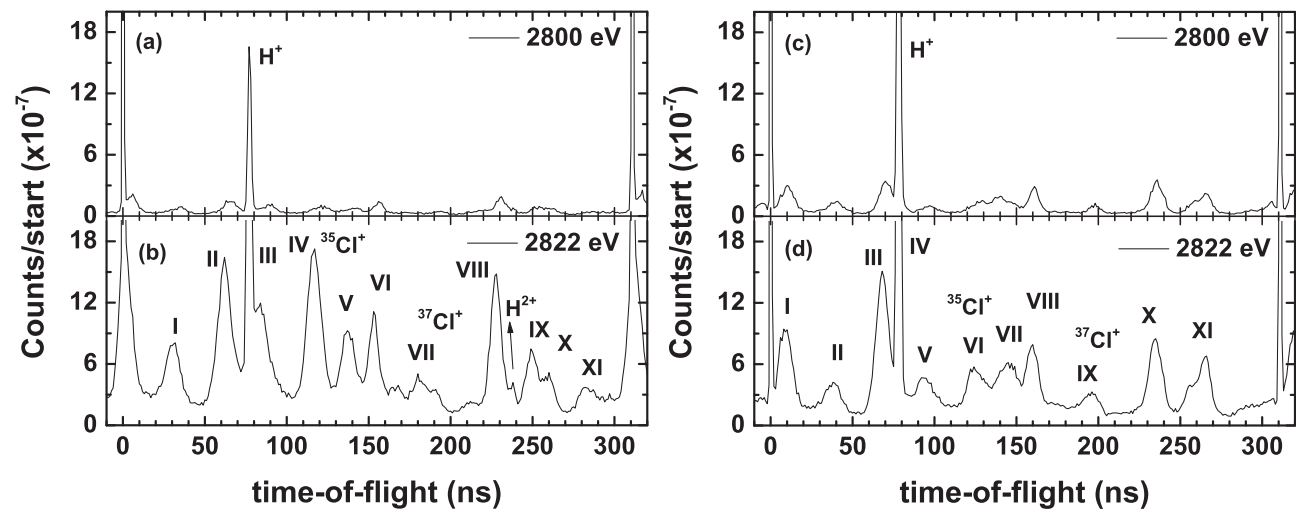

Fig. 3. PSID spectra obtained for (a) PVC at $2800 \mathrm{eV}$; (b) PVC at $2822 \mathrm{eV;} \mathrm{(c)} \mathrm{PVDC} \mathrm{at} 2800 \mathrm{eV}$ and (d) PVDC at $2822 \mathrm{eV}$ 
Table 1

Possible ions generated from $\mathrm{Cl}$ 1s-edge photoexcitation of PVC

\begin{tabular}{|c|c|c|c|}
\hline Peak & TOF exp (ns) & Mass (a.m.u) & Possible assignment \\
\hline I & 30.8 & 79 & $\mathrm{C}_{3} \mathrm{H}_{7} \mathrm{Cl}^{+}$ \\
\hline II & 61.2 & 67 & $\mathrm{C}_{5} \mathrm{H}_{7}^{+}$ \\
\hline III & 76.8 & 1 & $\mathrm{H}^{+}$ \\
\hline IV & 116.7 & 35 & ${ }^{35} \mathrm{Cl}^{+}$ \\
\hline \multirow[t]{2}{*}{ V } & 137.6 & 19 & $\mathrm{H}_{3} \mathrm{O}^{+}$ \\
\hline & & 70 & $\mathrm{Cl}_{2}^{+}$ \\
\hline \multirow[t]{2}{*}{ VI } & 154.1 & 27 & $\mathrm{C}_{2} \mathrm{H}_{3}^{+}$ \\
\hline & & 36 & $\mathrm{HCl}^{+}$ \\
\hline \multirow[t]{2}{*}{ VII } & 180.9 & 37 & ${ }^{37} \mathrm{Cl}^{+}$ \\
\hline & & 59 & $\mathrm{C}_{2} \mathrm{Cl}^{+}$ \\
\hline \multirow[t]{4}{*}{ VIII } & 227.9 & 29 & $\mathrm{C}_{2} \mathrm{H}_{5}^{+}$ \\
\hline & & 49 & $\mathrm{CH}_{2} \mathrm{Cl}^{+}$ \\
\hline & & 61 & $\mathrm{C}_{2} \mathrm{H}_{2} \mathrm{Cl}^{+}$ \\
\hline & & 74 & $\mathrm{C}_{3} \mathrm{H}_{2} \mathrm{Cl}^{+}$ \\
\hline \multirow[t]{4}{*}{ IX } & 249.9 & 39 & $\mathrm{C}_{3} \mathrm{H}_{3}^{+}$ \\
\hline & & 50 & $\mathrm{CH}_{3} \mathrm{Cl}^{+}$ \\
\hline & & 62 & $\mathrm{C}_{2} \mathrm{H}_{3} \mathrm{Cl}^{+}$ \\
\hline & & 75 & $\mathrm{C}_{3} \mathrm{H}_{3} \mathrm{Cl}^{+}$ \\
\hline \multirow[t]{5}{*}{$\mathrm{X}$} & 259.2 & 15 & $\mathrm{CH}_{3}^{+}$ \\
\hline & & 30 & $\mathrm{C}_{2} \mathrm{H}_{6}^{+}$ \\
\hline & & 90 & $\mathrm{C}_{8} \mathrm{H}_{6}^{+}, \mathrm{C}_{4} \mathrm{H}_{7} \mathrm{Cl}^{+}, \mathrm{C}_{4} \mathrm{H}_{5} \mathrm{Cl}^{+}$ \\
\hline & & 106 & $\mathrm{C}_{5} \mathrm{H}_{6} \mathrm{Cl}^{+}$ \\
\hline & & 123 & $\mathrm{C}_{10} \mathrm{H}_{2}^{+}, \mathrm{C}_{4} \mathrm{H}_{4} \mathrm{Cl}_{2}^{+}, \mathrm{C}_{7} \mathrm{H}_{4} \mathrm{Cl}^{+}$ \\
\hline XI & 281.3 & 63 & $\mathrm{C}_{2} \mathrm{H}_{4} \mathrm{Cl}^{+}$ \\
\hline
\end{tabular}

Table 2

Possible ions generated from $\mathrm{Cl}$ 1s-edge photoexcitation of PVDC.

\begin{tabular}{|c|c|c|c|}
\hline Peak & TOF exp (ns) & Mass (a.m.u.) & Possible assignment \\
\hline \multirow[t]{2}{*}{ I } & & 52 & $\mathrm{C}_{4} \mathrm{H}_{4}^{+}$ \\
\hline & 9.3 & 78 & $\mathrm{C}_{6} \mathrm{H}_{6}^{+}$ \\
\hline II & 37.9 & 79 & $\mathrm{C}_{6} \mathrm{H}_{7}^{+}, \mathrm{C}_{3} \mathrm{H}_{7} \mathrm{Cl}^{+}, \mathrm{C}_{3} \mathrm{H}_{5} \mathrm{Cl}^{+}$ \\
\hline III & 67.7 & 67 & $\mathrm{C}_{5} \mathrm{H}_{7}^{+}$ \\
\hline IV & 78.0 & 1 & $\mathrm{H}^{+}$ \\
\hline \multirow[t]{2}{*}{$\mathrm{V}$} & 93.0 & 68 & $\mathrm{C}_{5} \mathrm{H}_{8}^{+}$ \\
\hline & & 35 & ${ }^{35} \mathrm{Cl}^{+}$ \\
\hline \multirow[t]{2}{*}{ VI } & 123.9 & 69 & $\mathrm{C}_{5} \mathrm{H}_{9}^{+}$ \\
\hline & & 83 & $\mathrm{CHCl}_{2}^{+}$ \\
\hline \multirow[t]{3}{*}{ VII } & 144.9 & 70 & $\mathrm{Cl}_{2}^{+}$ \\
\hline & & 13 & $\mathrm{CH}^{+}$ \\
\hline & & 27 & $\mathrm{C}_{2} \mathrm{H}_{3}^{+}$ \\
\hline \multirow[t]{3}{*}{ VIII } & 160.2 & 36 & $\mathrm{HCl}^{+}$ \\
\hline & & 85 & $\mathrm{CH}^{35,37} \mathrm{Cl}_{2}^{+}$ \\
\hline & & 100 & $\mathrm{C}_{8} \mathrm{H}_{4}^{+}, \mathrm{C}_{5} \mathrm{H}_{5} \mathrm{Cl}^{+}$ \\
\hline \multirow[t]{3}{*}{ IX } & 195.5 & 37 & ${ }^{37} \mathrm{Cl}^{+}$ \\
\hline & & 2 & $\mathrm{H}_{2}^{+}$ \\
\hline & & 29 & $\mathrm{C}_{2} \mathrm{H}_{5}^{+}$ \\
\hline \multirow[t]{5}{*}{$\mathrm{X}$} & 234.3 & 49 & $\mathrm{CH}_{2} \mathrm{Cl}^{+}$ \\
\hline & & 61 & $\mathrm{C}_{2} \mathrm{H}_{2} \mathrm{Cl}^{+}$ \\
\hline & & 74 & $\mathrm{C}_{3} \mathrm{H}_{2} \mathrm{Cl}^{+}$ \\
\hline & & 15 & $\mathrm{CH}_{3}^{+}$ \\
\hline & & 30 & $\mathrm{C}_{2} \mathrm{H}_{6}^{+}$ \\
\hline \multirow[t]{3}{*}{ XI } & 266.1 & 50 & $\mathrm{C}_{4} \mathrm{H}_{2}^{+}$ \\
\hline & & 62 & $\mathrm{C}_{2} \mathrm{H}_{3} \mathrm{Cl}^{+}$ \\
\hline & & 75 & $\mathrm{C}_{3} \mathrm{H}_{3} \mathrm{Cl}^{+}$ \\
\hline
\end{tabular}

surface, and cannot be detected. Due to this observation and to its valence mass spectra [26], the observed PSID peaks were assigned considering only mass to charge ratios up to 100 .

Desorption ion yield (DIY) curves for $\mathrm{Cl}^{+}$species desorbed from chlorinated polymeric films are plotted as a function of the photon energy in Fig. 4. In order to present both DIY curves in the same graph, the PVDC curve has been multiplied by a factor of 3 . Both chlorinated polymer films show a maximum in the ion yield at the $\mathrm{Cl} 1 \mathrm{~s}$-resonance energy. Contributions from the XESD process to the generation of the $\mathrm{Cl}^{+}$photofragmentation and desorption

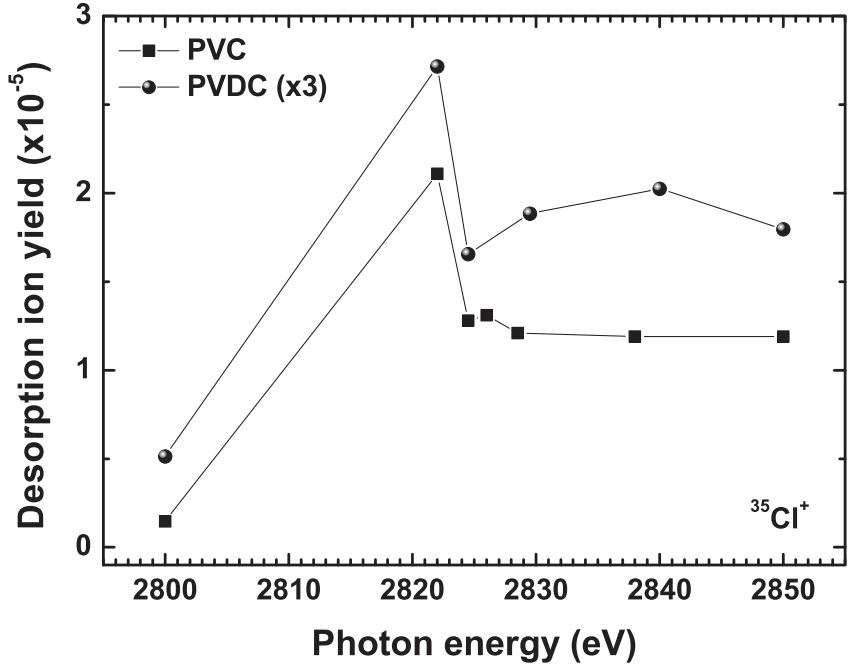

Fig. 4. Desorption ion yield curves for $\mathrm{Cl}^{+}$for (a) PVC and (b) PVDC films as a function of the photon energy.

Table 3

Edge jumps (B, D and E) and edge jump ratios (B/D and B/E) of electron and ion yields calculated for $\mathrm{Cl}^{+}$species from PVC and PVDC films.

\begin{tabular}{llllll}
\hline \multirow{2}{*}{ Photon energy } & \multicolumn{2}{l}{ PVC film } & & \multicolumn{2}{l}{ PVDC film } \\
\cline { 2 - 3 } \cline { 5 - 6 } & Electron yield & Ion yield & & Electron yield & Ion yield \\
\hline B & 41.5 & 14.4 & & 34.2 & 5.30 \\
$\mathrm{D}$ & 31.0 & 8.23 & & 31.2 & 3.66 \\
$\mathrm{E}$ & 27.8 & 8.10 & & 27.0 & 3.94 \\
$\mathrm{~B} / \mathrm{D}$ & 1.34 & 1.75 & & 1.10 & 1.45 \\
$\mathrm{~B} / \mathrm{E}$ & 1.49 & 1.78 & & 1.27 & 1.34 \\
\hline
\end{tabular}

due to single and multiple valence excitations and ionizations should also be considered, since the XESD signal is proportional to the electron yield in the NEXAFS spectrum.

In order to evaluate the XESD contribution to the $\mathrm{Cl}^{+}$desorption, we estimated the ratio of electron yield (from NEXAFS spectrum) and ion yield (from PSID spectrum) above and below the absorption edge (edge-jump) [12], whose values are presented in Table 3 , namely, B, D and E.

Comparison between ion and electron yield ratios obtained from the ratio between the edge-jumps of the different transitions in the spectrum, namely, B/D and B/E (edge-jump ratios) given in Table 3 shows that the two chlorinated polymers present higher ion yield ratios, indicating site-selectivity in breaking the $\mathrm{C}-\mathrm{Cl}$ bond at the $\mathrm{Cl} 1 \mathrm{~s}$ absorption resonance, as observed and discussed in the literature for other chlorinated molecules $[12,27]$. Similar results were obtained for these polymers at the chlorine $2 \mathrm{p}$ absorption edge [15], which once again exemplify the important contribution of the spectator Auger decay to break chemical bonds selectively [12].

\section{Conclusions}

Two chlorinated polymeric films, PVC and PVDC, have been investigated using PSID and NEXAFS techniques around the chlorine 1s-edge. The spectator Auger decay plays an important role for the desorption of the $\mathrm{Cl}^{+}$species at the chlorine 1s-resonance, as observed previously at the chlorine 2p-edge. This behavior was not observed at valence or carbon 1s-edge excitations. By comparing the two chlorinated polymers, a decrease of the relative 
intensity of $\mathrm{Cl}^{+}$species occurs for PVDC, a direct consequence of the fact that the photoabsorption signal is enhanced for PVC as corroborated by our theoretical calculations, which also demonstrated the antibonding character of the molecular orbital involved in the first $\mathrm{Cl} 1 \mathrm{~s}$-electronic transition. The expected 3:1 isotope ratio is clearly observed for the PVC film, as obtained previously by electron stimulated ion desorption. The enhancement in the $\mathrm{Cl}^{+}$ion yields as compared to the electron yield was observed at the first resonance for both chlorinated polymers and the spectator Auger decay was invoked to interpret these results. On the other hand, the production of $\mathrm{H}^{+}$and molecular fragments observed in all photon energies is induced mainly by the indirect process. Clear evidence of chemical bond breaking controlled by a deep core level excitation is presented.

\section{Acknowledgments}

Research partially supported by National Synchrotron Light Laboratory (LNLS), Brazil. The authors would like to thank Conselho Nacional de Desenvolvimento Científico e Tecnológico (CNPq), Coordenação de Aperfeiçoamento de Pessoal de Nível Superior (CAPES), Fundação de Amparo à Pesquisa do Estado do Rio de Janeiro (FAPERJ) and Fundação de Amparo à Pesquisa do Estado de Minas Gerais (FAPEMIG) for financial support.

\section{References}

[1] P.D. Zygoura, E.K. Paleologos, M.G. Kontominas, Food Chem. 128 (2011) 106.

[2] K. Silapasorn, K. Sombatsompop, A. Kositchaiyong, E. Wimolmala, T. Markpin, N. Sombatsompop, J. Appl. Pol. Sci. 121 (2011) 253.

[3] A.A. Haroun, E.F. Ahmed, M.A.A. El-Ghaffar, J. Mater. Sci: Mater. Med. 22 (2011) 2545 .
[4] Nuriman, B. Kuswandi, W. Verboom, Sens. Actuators B: Chem. 157 (2011) 438.

[5] M.L.M. Rocco, G.V. Mota, R.R. Pinho, J. Electron Spectrosc, Relat. Phenom. 151 (2006) 135.

[6] M.L.M. Rocco, G.S. Faraudo, F.C. Pontes, R.R. Pinho, M. Ferreira, G.G.B. de Souza, Chem. Phys. Lett. 393 (2004) 213.

[7] M.L.M. Rocco, F.C. Pontes, G.S. Faraudo, G.G.B. de Souza, Pol. Deg. Stab. 88 (2005) 213.

[8] L.A.V. Mendes, S.D. Magalhaes, C. Arantes, M.L.M. Rocco, Pol. Deg Stab. 92 (2007) 741

[9] M.L.M. Rocco, G.S. Faraudo, R.R. Pinho, M. Ferreira, F.C. Pontes, G.G.B. de Souza, J. Electron Spectrosc, Relat. Phenom. 141 (2004) 1.

[10] M.L.M. Rocco, G.S. Faraudo, F.C. Pontes, G.G.B. de Souza, R.R. Pinho, M. Ferreira, Braz. J. Phys. 36 (2006) 534.

[11] E.C. Rangel, N.M. dos Santos, J.R.R. Bortoleto, S.F. Durrant, W.H. Schreiner, R.Y. Honda, R.C.C. Rangel, N.C. Cruz, Appl. Surf. Sci. 258 (2011) 1854.

[12] Y. Baba, K. Yoshii, T.A. Sasaki, Surf. Sci. 376 (1997) 330.

[13] R.Z. Bachrach, V. Rehn, R.A. Rosenberg (Ed.), Synchrotron Radiation Research: Advances in Surface and Interface Science - Techniques, vol. 1, Plenum Press, New York, 1992.

[14] M.L. Knotek, Rep. Prog. Phys. 47 (1984) 1499

[15] Y. Baba, Low Temp. Phys. 29 (2003) 228. and references therein.

[16] M.C. Corrêa, H. Tolentino, A. Craievich, C. Cusatis, Rev. Sci. Instrum. 63 (1992) 896.

[17] M.L.M. Rocco, D.E. Weibel, L.S. Roman, L. Micaroni, Surf. Sci. 560 (2004) 45.

[18] J.A. Bearden, A.F. Burr, Rev. Mod. Phys. 39 (1967) 125

[19] J.L. Wiza, Nucl. Instrum. Methods Phys. Res. Sect. B 162 (1979) 587.

[20] D.A. Dahl, Simion 3D version 6.0 user manual, Idaho National Engineering Laboratory, 1995.

[21] D.E. Weibel, M.L.M. Rocco, F.C. Pontes, M. Ferreira, G.G.B. de Souza, Pol. Deg. Stab. 91 (2006) 712.

[22] H. Nakano, R. Uchiyama, K. Hirao, J. Comput. Chem. 23 (2002) 1166.

[23] M. Douglas, N.M. Kroll, Ann. Phys. 82 (1974) 89.

[24] B.A. Hess, Phys. Rev. A 33 (1986) 3742.

[25] T. Nakajima, K. Hirao, J. Chem. Phys. 113 (2000) 7786.

[26] NIST Chemistry Webbook, United States of, America (2011). (webbook.nist.gov/chemistry).

[27] Y. Baba, K. Yoshii, T.A. Sasaki, Surf. Sci. 402-404 (1998) 115

[28] M.W. Schmidt, K.K. Baldridge, J.A. Boatz, S.T. Elbert, M.S. Gordon, J.H. Jensen, S. Koseki, N. Matsunaga, K.A. Nguyen, S.J. Su, T.L. Windus, M. Dupuis, J.A Montgomery, J. Comput. Chem. 14 (1993) 1347. 